\title{
Quantum Chemical Investigation on D-ז-A Based Phenothiazine Organic Chromophores with Spacer and Electron Acceptor Effect for DSSCs
}

Anbarasan Ponnusamy Munusamy ( $\sim$ profpmanbarasan@gmail.com )

Periyar University https://orcid.org/0000-0001-7396-9822

Arunkumar Ammasi

Periyar University

Shanavas Shajahan

Periyar University

Tansir Ahamad

King Saud University

\section{Research Article}

Keywords: D-ח-A Configuration, DFT and TD-DFT Calculations, CAM-B3LYP Functional, Electronic and Absorption Spectra, DSSCs

Posted Date: March 3rd, 2021

DOI: https://doi.org/10.21203/rs.3.rs-259041/v1

License: (c) (i) This work is licensed under a Creative Commons Attribution 4.0 International License. Read Full License 


\title{
Quantum Chemical Investigation on D- $\pi$-A Based Phenothiazine Organic Chromophores with Spacer and Electron Acceptor Effect for DSSCs
} Anbarasan Ponnusamy Munusamy ${ }^{1 *}$, Arunkumar Ammasi ${ }^{1}$, Shanavas Shajahan ${ }^{1}$, Tansir Ahamad $^{2}$

${ }^{1}$ Department of Physics, Periyar University, Salem - 636011 , India.

${ }^{2}$ Department of Chemistry, College of Science, King Saud University, P.O. Box 2455, Riyadh 11451, Saudi Arabia.

\begin{abstract}
In this work, the newly designed phenothiazine based organic dye (PT-BTBA, PT-EBTBA and PT-EBTEBA) derivatives were screened and investigated for dye-sensitized solar cells (DSSCs) application. The literature dye of SB covers the electron-donor (D) in phenothiazine and cyanoacrylic acid in electron-acceptor (A) based on D-A structure. In order to improving the $\pi$ conjugation and acceptor effects on the SB dye were investigated. The effect of D- $\pi$-A designed dyes on the optical absorption spectra and photovoltaic (PV) parameters were implemented by the density functional theory (DFT) and time-dependent DFT (TD-DFT) calculations. Also, the hybrid functionals were initially evaluated to establish an accurate methodology for calculating the first-singlet absorption peak of SB dye. Consequently, TD-CAM-B3LYP functional and 6$311++\mathrm{G}(\mathrm{d}, \mathrm{p})$ theory were well match with the literature data. According to this result, phenothiazine-4-((7-ethynylbenzo[c][1,2,5]thiadiazol-4-yl)ethynyl)benzoic acid (PT-EBTEBA) dye has the strong group for more red-shifted and successfully electron inject into $\mathrm{TiO}_{2}$ surface. It is expected to provide some theoretical guidance on designing photosensitive with new metalfree organic dyes for use in DSSCs yielding highly efficient performance.
\end{abstract}

Keywords: D- $\pi$-A Configuration; DFT and TD-DFT Calculations; CAM-B3LYP Functional; Electronic and Absorption Spectra; DSSCs.

\section{*Corresponding author:}

P. M. Anbarasan

Tel: +91 $04272345766 / 2345520$

Fax: +91 $04272345565 / 2345124$

Email address: profpmanbarasan@gmail.com 


\section{Introduction}

Michael Gratzel and O'Regan groups were first developed by the dye-sensitized solar cells (DSSCs) in 1991, it was converted light energy into electricity [1]. In photovoltaic (PV) device, DSSCs components were contained the conduction band edge (CBE) of semiconductor titanium dioxide $\left(\mathrm{TiO}_{2}\right)$ surface, photoanode sensitized dyes, redox shuttle and counter electrode, respectively [2]. Furthermore, sensitizers can be divided into two categories: (i). Metal complex and (ii). Metal-free organic dye has one of the key components for high power conversion efficiency (PCE) in DSSCs. Recently, the scientific research report were conducted by PCE up to $24.2 \%$, but the conventional electricity production process is still noncompetitive [3]. Metal-free organic sensitizers contain the donor (D), $\pi$-bridge $(\pi)$ and acceptor (A) (D- $\pi$-A) have feasible flexibility for molecular proposal in DSSCs. Also, D- $\pi$-A pattern of the dyes were strongly desirable because of their several features, such as large absorption wavelength, high efficiency, tunable molecules with optoelectronic properties, lower cost large-scale production, easier preparation and purification, etc. [4-7]. Other major advantages of the organic sensitizers were cover the tunable absorption wavelength and PV properties over suitable molecular architecture [8, 9]. In literature, novel organic merocyanine [10], cyanine [11], hemicyanine [12], triphenylamine [13-16], dialkylaniline [17], phenothiazine [18], tetrahydroquinoline [19], coumarins [20-23], indoline [24-27] and carbazole [28] dyes were successfully investigated and proven for DSSCs application. For example, Kar groups reported on N, N'-dialkylaniline (NDI 6) based DSSCs were exhibits by PCE upto 19.24\% [29].

Highly efficient organic photosensitizer for DSSCs must have the following properties [30]: First, dye absorbs most of the sunlight or light rays, a broad absorption range that covers together the Ultraviolet-Visible (UV-Vis) and near-infrared (N-IR) regions. Secondly, an intramolecular charge transfer (ICT) from electronic-D and A moieties is one of the main characteristics of organic DSSCs [31-35]. Third, the suitable energy level of the highest occupied molecular orbitals (HOMOs) must be below the redox potential $I^{-} / I_{3}^{-}$of the electrolyte. Consequently, the oxidized sensitizer that have lose electrons is then turned back to the ground state of a redox system. Also, lowest unoccupied MOs (LUMOs) of the dyes must be above the conduction band edge (CBE) of the $\mathrm{TiO}_{2}$ semiconductor metal oxide. Thus, excited state molecules electrons can be efficiently injected into the $\mathrm{TiO}_{2}$ surface. The D- $\pi$-A structure with 
acceptor directly bonded to the semiconductor surface, which favor efficient charge transfer (CT) to the $\mathrm{CBE}$ of $\mathrm{TiO}_{2}$ and regeneration to the ground state of dyes [36].

In 2011, Derong Cao synthesized a D-A based SB dye is a simple structure of the organic chromophore with a phenothiazine group as a donor and 2-cyanoacrylic acid as acceptor. The electron rich nature of a phenothiazine group were delivered a good spread for the electron movement from D to A. According to SB-based DSSCs were exhibits a power conversion efficiency (PCE) $2.91 \%$, high photocurrent $(6.13 \mathrm{~mA} \mathrm{~cm}$ ) and photovoltage $(709 \mathrm{mV})$ measured at under AM 1.5G irradiation [37]. The PCE of DSSCs was generally determined by the short-circuit current density $\left(J_{S C}\right)$, open-circuit photovoltage $\left(V_{O C}\right)$ and the fill factor $(F F)$. Furthermore, the improvement of $J_{S C}$ and $V_{O C}$ would be significantly enhance the PCE.

Additionally, spacer and the acceptor group effects of dyes play a key role on $\mathrm{TiO}_{2}$ surface. It has been improve efficiency of the organic solar cell. In this study, 4-(benzo[c][1,2,5]thiadiazol-7-yl)benzoic acid (BTBA), 4-(7-ethynylbenzo[c][1,2,5]thiadiazol-4-yl)benzoic acid (EBTBA), 4-((7-ethynylbenzo[c][1,2,5]thiadiazol-4-yl)ethynyl)benzoic acid (EBTEBA) were used as the spacer and acceptor groups [38]. The designed dye names were denoted by PTBTBA, PT-EBTBA and PT-EBTEBA. Scheme 1 display that the spacer and electron-A effect of the $\mathrm{D}-\pi$-A sensitizers were under investigation. Furthermore, a detailed inspect on photosensitizing properties of PT-BTBA, PT-EBTBA and PT-EBTEBA derivatives were determined by density functional theory (DFT) and time-dependent DFT (TD-DFT) calculations. The calculated result PT-EBTEBA were represent that the smaller energy gap, vertical absorption coefficient obviously red-shift and development of organic DSSCs.

\section{Computational Details}

The quantum chemical investigation were recognized as a powerful instrument. It has been used to the electronic configuration and numerous belongings of dye sensitizers. The ground-state geometries of the designed dyes were fully optimized by DFT with the B3LYP [39] and 6$31 \mathrm{G}(\mathrm{d}, \mathrm{p})$ theory. The optimized geometry results were executed by without any symmetry constraints, it has been broadly used for theoretical DSSCs research. The optimized dye structures were found at its local minima (no imaginary frequency modes) on the potential energy surfaces. 
The previous TD-DFT valuation suggested that extremely efficient and reliable calculation of vertical excitation energies, photoabsorption spectra and PV properties [40, 41]. In reliability of DSSCs, the great effects of the exchange (XC) and long-range corrected (LC) functionals were used for absorption peak. In this work, XC \& LC functionals such as B3LYP, CAM-B3LYP [42], P3PW91 [43] and $₫ B 97 X D$ [44] methods were analyzed for UV-Vis peak. From the functionals, SB dye absorption peak calculated values were listed in table 1. From the table, the absolute values were 507, 427, 508 and 398 nm, respectively. From the results, CAMB3LYP functional was display nearly well matched to SB $(439 \mathrm{~nm})$ with errors of more or less 68, 12, 69 and $41 \mathrm{~nm}$. Consequently, TD-CAM-B3LYP/6-311++G(d,p) theory has discovered to be the reliable functional for prediction of UV-Vis spectra. The solvent effects were included by the conductor-like polarizable continuum model (C-PCM) [45, 46]. During the research, as per literature tetrahydrofuran (THF) solvent were used in SB dye. Also, CAM-B3LYP was successfully employed for calculating the absorption spectra of the designed dyes. The absorption spectra were calculated by GaussSum 3.0 version [47]. The DFT and TD-DFT calculations of the dyes were accomplished by Gaussian 09w suite [48].

\section{Results and Discussion}

\section{Screening of the Dyes and Optimized Structures}

The spacer and electron acceptor groups are a key parameter with D- $\pi$-A structure for highperformance of organic DSSCs. We selected three functional types, which might be made for the addition of chemical modified in conjugation and acceptor. The substituent groups have been given as the collected from literature as discussed above. From the preceding study, those molecules are good performing for organic DSSCs application. In this manner, those dyes may be stimulated to the phenothiazine based dye derivatives. A newly designed dyes in PT-BTBA, PT-EBTBA and PT-EBTEBA were investigated by the DFT and TD-DFT systematically. The optimized geometric structures of the SB and designed dyes were performed by the B3LYP/6$31 \mathrm{G}(\mathrm{d}, \mathrm{p})$ level of theory and shown in Fig. 1. As shown in figure, the geometry structures of the dyes were shown that the better coplanar configurations. Also, the coplanar structure designates that the photosensitizers were fully conjugated throughout the $D-\pi-A$ pattern. It has been favorable for the photo-induced CT from the electron D-A and also accelerating electron 
injection to the $\mathrm{CBE}$ of $\mathrm{TiO}_{2}$ surface. Additionally, the introduced $\pi$-conjugation and acceptor part were favored to the broadening absorption wavelengths.

\section{Electronic Structures and Frontier Molecular Orbitals (FMOs) of the Planned Dyes}

Frontier molecular orbitals (FMOs) is a very crucial factor in defining the charge separated states of dye sensitizers [49]. The FMOs of PT-BTBA, PT-EBTBA and PT-EBTEBA were recognized with admire in electron CT states for all dyes. The influence of the spacer and acceptor in HOMOs and LUMOs were obtained at the optimized structures using B3LYP/6-31G(d,p) level and shown in Fig. 2. To make a capable charge-divided by photoabsorption, it is desirable that the HOMOs were predominantly contained in the donor fragment of phenothiazine and $\pi$-spacer, LUMOs were localized on the $\pi$-spacer and electron acceptor moiety of benzoic acid (generally on the anchoring area). The electron dispersal indicated that the best CT character among the HOMOs and LUMOs. As shown in Figure 2, isodensity contour plots of the all dyes were efficient for CT. The HOMOs and LOMOs energies shown that possible responsible for the development of PV properties in organic DSSCs. As displayed in table 2, HOMOs and LUMOs energy values were $-5.30,-5.20,-5.12,-4.99 \mathrm{eV}$ and $-3.01,-2.95,-2.98,-2.92 \mathrm{eV}$, respectively. Moreover, the calculated energy gap $\left(E_{g}\right)$ values of the studied compounds were 2.29, 2.25, 2.14, $2.07 \mathrm{eV}$, respectively.

The HOMOs energy level must have lower than the redox potential $I^{-} / I_{3}^{-}$of electrolyte $(-4.80 \mathrm{eV})$ [50]. Similarly, all the LUMOs energies have to be capable of injecting electrons into the $\mathrm{CBE}$ of $\mathrm{TiO}_{2}(-4.0 \mathrm{eV})$ surface [50]. According to fig. 3, all LUMOs energies dyes lie over the $\mathrm{CBE}$ of $\mathrm{TiO}_{2}$ and the HOMOs were situated below the redox couple. As shown in figure 3 and table 2, energy levels of the all designed dye compounds has smaller $E_{g}$, compared to SB. In particular, PT-EBTEBA dye can be identified that the positive response to wider absorption region and regeneration with photo-oxidation manner.

\section{Optical Absorption Properties}

Firstly, the optical absorption peak of SB dye was used four different functionals (B3LYP, CAM-B3LYP, P3PW91 and $₫ B 97 X D$ ) with THF solvent and TD-DFT calculation (Table 1 and Figure 1). According to the best of functional, designed dye derivatives have been calculated at TD-CAM-B3LYP/6-311++G(d,p) theory with THF medium. The simulated absorption spectra 
and corresponding calculated vertical excitation energy $(E)$, oscillator strengths (f), major and minor orbital contributions (\%) of the dyes have been listed table 3 and shown in Fig. 4 and. From the figure, all the organic dyes have shown extensive visible around $600 \mathrm{~nm}$, which is related to ICT character. Normally, the molecular dyes with broader wavelengths and enhanced molar extinction coefficients are predicted to have higher photo-to-current conversion efficiency of DSSCs performance [51].

As shown in table 3, the calculated maximum optical absorption wavelengths of the planned dyes were 388, 464 and $506 \mathrm{~nm}$, respectively. In particular, PT-EBTEBA sensitizer has the longer absorption spectrum compared to other dyes and SB (427 nm). Also, the vertical excitation energies of the dyes were $2.68,2.67$ and $2.44 \mathrm{eV}$, respectively. All the derivative sensitizers have shown red-shifts, compared to SB dye. The longer wavelengths were assigned to the ICT among the D to electron-A, and the shorter peaks were assigned to the localized $\pi-\pi^{*}$ transitions within organic dyes. Moreover, the strongest absorption spectra of dyes were arising from $n \rightarrow \pi^{*}$ transitions. From table 3 , the $E$ were decreased order: PT-EBTBA $>$ PT-BTBA $>$ PTEBTEBA showing that there has a red-shifts when passing from PT-EBTBA. The calculated results indicated that a PT-EBTEBA sensitizer more redshift at the long-wavelength side, which was promoted to further increase of the corresponding DSSCs.

\section{PV Properties}

\section{Power Conversion Efficiency}

PCE of the DSSCs have been calculated by using Eq. (1) [52]:

$$
\eta=\frac{J_{S C} V_{O C} F F}{P_{I N C}}
$$

Where $P_{I N C}$ designates incident power density. In DSSCs, $V_{O C}$ is predominantly determined by the difference between redox electrolyte and $\mathrm{CBE}$ of $\mathrm{TiO}_{2}$. Commonly, the solution $I^{-} / I_{3}^{-}$is used as the redox shuttle, it is able to be taken as a constant. The shift of CBE can be determined by using the formulation to earlier studies [53]. The $\mu_{\text {normal }}$ is another crucial characteristic that delivers the vertical electronic charge dispersal in the dye molecules. As proven in figure S0 (supporting information), if $\mu_{\text {normal }}$ was excessive to a more extent shift of CBE the outcome has been large $V_{O C}$. 
As shown in table 4, the dipole moment values of PT-BTBA, PT-EBTBA and PTEBTEBA are 6.01, 7.80 and 8.31 Debye, respectively. Also, all the dyes may have possible response a larger $V_{O C}$. In particular, a higher values of PT-EBTEBA can be very good act for $V_{O C}$, compared to SB (4.55 Debye). Among three dyes, PT-EBTEBA may be the best performance for excessive conversion efficiency of DSSCs. As for $J_{S C}$, it is a crucial part for DSSCs calculated by the formulations previous study [54] and the corresponding factors are discussed below. In order to attain extreme $J_{S C}, L H E$ of the dye molecules necessity to be as high as possible.

$\operatorname{LHE}(\lambda)$ can be described by the following equation [55]:

$$
\operatorname{LHE}(\lambda)=1-10^{-f}
$$

Where $\mathrm{f}$ signifies oscillator strength of associated dye molecules related to the absorption peak. So as to provide a needful of the spacer and electron acceptor, we simulated to the absorption spectra of the dyes with affecting the $L H E$. The calculated $L H E$ values of the PT-BTBA, PTEBTBA and PT-EBTEBA dye molecules were given in the range from 0.76 to 0.92 a.u., respectively. Based on $L H E$ of the sensitizers, the values have to be high as probable to maximize the photocurrent reply for DSSCs. As displayed in table 4 and figure 5a, PT-EBTEBA dye has the highest value of LHE. Hence, all the sensitizers provided more or less similar photocurrent. In specific, PT-EBTEBA dye is more than the SB and other dyes, it has beneficial for $J_{S C}$.

\section{Electron Injection and Dye Regeneration}

Another method of increasing $J_{S C}$ influence factors of the dye regeneration $\left(\Delta G_{r e g}\right)$ electron injection $\left(\Delta G_{\text {inject }}\right)$ and oxidation potential energy $\left(E_{O X}^{d y e^{*}}\right)$ was calculated by using principles as defined in a previous study [56] and the calculated values are listed in table 4. The electronic possessions of the dyes in the first-singlet excited state is a main feature to increase the organic DSSCs. Theoretically proposed that $\Delta G_{\text {inject }}$ from the dye sensitized in the first excited state to $\mathrm{CBE}$ of $\mathrm{TiO}_{2}$ surface [57]. According to table 4 , it is observable that the $\Delta G_{\text {inject }}$ calculated values are negative, which means that the excited state of the dye lies above the $\mathrm{CBE}$ of $\mathrm{TiO}_{2}$. As said 
by Islam theory, $\Delta G_{\text {inject }}>0.2 \mathrm{eV}$ [58]. Consequently, absolute calculated values of the all planned dyes are much than $0.2 \mathrm{eV}$. Also, $\Delta G_{\text {inject }}$ energy values are given in the range from 1.45 to $-1.55 \mathrm{eV}$, respectively.

$J_{S C}$ is also enhanced by regeneration efficiency $\left(\Delta G_{r e g}\right)$ of the dyes. For a quicker CT, it is essential to lesser regeneration [59]. From Table 4, the absolute calculated values of the PTBTBA, PT-EBTBA and PT-EBTEBA are 0.40, 0.32, and $0.19 \mathrm{eV}$, respectively. The $\Delta G_{r e g}$ of the PT-EBTBA and PT-EBTEBA dyes can be fastest regenerated, which is increased for $J_{S C}$. Particularly, PT-EBTEBA dye is extreme PCE of the DSSCs.

\section{Open-Circuit Photovoltage}

Theoretical analysis of $e V_{O C}$ was determined by using the formulations as defined in an earlier study [60]. The $e V_{O C}$ calculated values are listed in Table 4 and presented in figure 5b. From the table, PT-BTBA, PT-EBTBA and PT-EBTEBA values are given in a range from 0.99 to 1.08 $\mathrm{eV}$, in these values is a promising response to the efficient electron injection. Also, larger values of the LUMOs will produce the higher $e V_{O C}$, which is provided to PCE of the DSSCs.

According to figure 5b, it has shown that the PT-BTBA and PT-EBTEBA dyes larger $e V_{O C}$ value, compared to SB dye. In specific, PT-EBTEBA dye has a higher $e V_{O C}$, which identify that the extraordinary performance of organic DSSCs. Therefore, PT-EBTEBA dye has used for the dye-sensitized, owing to their electron injection technique from the excited state sensitizers into the $\mathrm{CBE}$ of $\mathrm{TiO}_{2}$ have been successful.

\section{Exciton Binding Energy $\left(E_{b}\right)$}

To get high PCE in DSSCs, the electron-hole pairs should be split into separate negative and positive charges to escape from recombination owing to coulombic forces. During this procedure, the binding energy need be overcome; that is, the dyes must take lower exciton binding energy to attain high PCE of DSSCs. The exciton binding energy was followed by using the formula in earlier studies $[61,62]$ and the values are listed in table 4. From the table, PTBTBA, PT-EBTBA and PT-EBTEBA dyes absolute calculated values are $0.43,0.53$ and 0.37 $\mathrm{eV}$, respectively. As shown in figure 5c and table 4, PT-EBTEBA dye is smaller value than the 
other molecules and SB. It can be noted that PT-EBTEBA dye has lesser than the other sensitizers and SB $(0.61 \mathrm{eV})$, which denotes that the excellent act for DSSCs.

\section{Conclusion}

A sequence of three isolated metal-free organic DSSCs totally on the PT-BTBA, PT-EBTBA and PT-EBTEBA became successful with spacer and electron acceptor. The molecular orbital electronic structures, absorption properties and PCE influence parameters of the dyes were investigated systematically. In this study, the DFT and TD-DFT methods were discussed in detail to planning dye products. The calculated outcomes suggest that the screened with a spacer and the electron acceptor in PT-EBTEBA has promising functional organization for D- $\pi$-A form. Furthermore, the calculated results imply that the PT-EBTEBA dye has strong light harvesting efficiency, electron injection, electron transition, dye regeneration, open-circuit photovoltage, exciton binding energy and increasing the dipole moment, which benefits to higher PCE of DSSCs. It has concludes that the choice of the appropriate screened with spacer and electron acceptor. Finally, these are very important for the molecular design of phenothiazine based highly efficient organic solar cells.

\section{Acknowledgements}

The authors extend their sincere appreciation to Researchers Supporting Project at King Saud University, Riyadh, Saudi Arabia for funding this research (2020/06).

\section{Funding}

King Saud University, Riyadh, Saudi Arabia (2020/06).

\section{Conflict of interest}

The authors declared that there is no conflict of interest.

\section{Availability of data and material}

All the data and electronic materials available for Gaussian program.

\section{Code availability}

Chemdraw, Gaussian 09w, Gaussview and Gausssum.

\section{Authors' contributions}

The manuscript was written through contributions of all authors. All authors have given approval to the final version of the manuscript. 


\section{References}

1. O'Regan B, Gratzel M (1991) A low-cost, high-efficiency solar cell based on dye sensitized colloidal $\mathrm{TiO}_{2}$ films. Nature 353:737-740.

2. Prima EC, Yuliarto B, Suendo V (2014) Improving photochemical properties of Ipomea pescaprae, Imperata cylindrica (L.) Beauv, and Paspalum conjugatum Berg as photosensitizers for dye sensitized solar cells. Journal of Materials Science: Materials in Electronics. 25:4603-4611.

3. Green MA, Emery K, Hishikawa Y, Warta W (2010) Solar cell efficiency tables (version 36). Prog Photovolt Res Appl 18:346.

4. Mishra A, Fischer MK, Bäuerle P (2009) Metal-free organic dyes for dye-sensitized solar cells: From structure: Property relationships to design rules. Angew Chem Int Ed 48:2474-2499.

5. Hagfeldt A, Boschloo G, Sun L, Kloo L, Pettersson H (2010) Dye-sensitized solar cells. Chem Rev. 110:6595-663.

6. Yen YS, Chou HH, Chen YC, Hsu CY, Lin JT (2012) Recent developments in moleculebased organic materials for dye-sensitized solar cells. J Mater Chem 22:8734-8747.

7. $\mathrm{Wu} \mathrm{Y,} \mathrm{Zhu} \mathrm{W} \mathrm{(2013)} \mathrm{Organic} \mathrm{sensitizers} \mathrm{from} \mathrm{D-} \pi$-A to D-A- $\pi$-A: effect of the internal electron-withdrawing units on molecular absorption, energy levels and photovoltaic performances. Cheml Soc Rev 42:2039-2058.

8. Arunkumar A, Prakasam M, Anbarasan PM (2017) Influence of Donor Substitution at D$\pi$-A Architecture in Efficient Sensitizers for Dye-Sensitized Solar Cells: First Principle Study. Bull Mater Sci 40:1389-1396.

9. Kitamura T, Ikeda M, Shigaki K, Inoue T, Anderson NA, Ai X, Lian T, Yanagida S (2004) Phenyl-conjugated oligoene sensitizers for $\mathrm{TiO}_{2}$ solar cells. Chem Mater 16:18061812.

10. Sayama K, Hara K, Mori N, Satsuki M, Suga S, Tsukagoshi S, Abe Y, Sugihara H, Arakawa H (2000) Photosensitization of a porous $\mathrm{TiO}_{2}$ electrode with merocyanine dyes containing a carboxyl group and a long alkyl chain. Chem Commun 13:1173-1174.

11. Ehret A, Stuhl L, Spitler MT (2001) Spectral sensitization of $\mathrm{TiO}_{2}$ nanocrystalline electrodes with aggregated cyanine dyes. J Phys Chem B 105:9960-9965. 
12. Wang ZS, Li FY, Huang CH (2000) Highly efficient sensitization of nanocrystalline $\mathrm{TiO}_{2}$ films with styryl benzothiazolium propylsulfonate. Chem Commun 20:2063-4.

13. Liang M, Xu W, Cai F, Chen P, Peng B, Chen J, Li Z (2007) New triphenylamine-based organic dyes for efficient dye-sensitized solar cells. J Phys Chem C 111:4465-4472.

14. Velusamy M, Justin Thomas KR, Lin JT, Hsu YC, Ho KC (2005) Organic dyes incorporating low-band-gap chromophores for dye-sensitized solar cells. Org Lett 7:1899-1902.

15. Tsai MS, Hsu YC, Lin JT, Chen HC, Hsu CP (2007) Organic dyes containing 1 Hphenanthro [9, 10-d] imidazole conjugation for solar cells. J Phys Chem C 111:18785-93.

16. Justin Thomas KR, Hsu YC, Lin JT, Lee KM, Ho KC, Lai CH, Cheng YM, Chou PT (2008) 2, 3-Disubstituted thiophene-based organic dyes for solar cells. Chem Mater 20:1830-40.

17. Hara K, Sato T, Katoh R, Furube A, Yoshihara T, Murai M, Kurashige M, Ito S, Shinpo A, Suga S, Arakawa H (2005) Novel conjugated organic dyes for efficient dye-sensitized solar cells. Adv Funct Mater 15:246-252.

18. Arunkumar A, Shanavas S, Anbarasan PM (2018) First-principles study of efficient phenothiazine-based D- $\pi$-A organic sensitizers with various spacers for DSSCs, J Comput Electron 17:1410-1420.

19. Chen R, Yang X, Tian H, Sun L (2007) Tetrahydroquinoline dyes with different spacers for organic dye-sensitized solar cells. J Photoch Photobio A: Chem 189:295-300.

20. Wang ZS, Hara K, Dan-oh Y, Kasada C, Shinpo A, Suga S, Arakawa H, Sugihara H (2005) Photophysical and (photo) electrochemical properties of a coumarin dye. J Phys Chem B 109:3907-3914.

21. Hara K, Sato T, Katoh R, Furube A, Ohga Y, Shinpo A, Suga S, Sayama K, Sugihara H, Arakawa H (2003) Molecular design of coumarin dyes for efficient dye-sensitized solar cells. J Phys Chem B 107:597-606.

22. Hara K, Kurashige M, Dan-oh Y, Kasada C, Shinpo A, Suga S, Sayama K, Arakawa H (2003) Design of new coumarin dyes having thiophene moieties for highly efficient organic-dye-sensitized solar cells. New J Chem 27:783-785. 
23. Hara K, Sayama K, Ohga Y, Shinpo A, Suga S, Arakawa H (2001) A coumarinderivative dye sensitized nanocrystalline $\mathrm{TiO}_{2}$ solar cell having a high solar-energy conversion efficiency up to 5.6\%. Chem Commun 6:569-70.

24. Ito S, Zakeeruddin SM, Humphry-Baker R, Liska P, Charvet R, Comte P, Nazeeruddin MK, Péchy P, Takata M, Miura H, Uchida S (2006) High-efficiency organic-dye-sensitized solar cells controlled by nanocrystalline- $\mathrm{TiO}_{2}$ electrode thickness. Adv Mater 18:1202-1205.

25. Schmidt-Mende L, Bach U, Humphry-Baker R, Horiuchi T, Miura H, Ito S, Uchida S, Grätzel M (2005) Organic dye for highly efficient solid-state dye-sensitized solar cells. Adv Mater 17:813-815.

26. Horiuchi T, Miura H, Uchida S (2004) Highly efficient metal-free organic dyes for dyesensitized solar cells. J Photoch Photobio A: Chem 164:29-32.

27. Horiuchi T, Miura H, Sumioka K, Uchida S (2004) High efficiency of dye-sensitized solar cells based on metal-free indoline dyes. J Am Chem Soc 126:12218-9.

28. Kim D, Lee JK, Kang SO, Ko J (2007) Molecular engineering of organic dyes containing $\mathrm{N}$-aryl carbazole moiety for solar cell. Tetrahedron 63:1913-22.

29. Kar S, Roy JK, Leszczynski J (2017) In silico designing of power conversion efficient organic lead dyes for solar cells using todays innovative approaches to assure renewable energy for future. NPJ Comput Mater 3:22.

30. Kim S, Lee JK, Kang SO, Ko J, Yum JH, Fantacci S, De Angelis F, Di Censo D, Nazeeruddin MK, Grätzel M (2006) Molecular engineering of organic sensitizers for solar cell applications. J Am Chem Soc 128:16701-7.

31. Liu P, Fu JJ, Guo MS, Zuo X, Liao Y (2013) Effect of the chemical modifications of thiophene-based $\mathrm{N} 3$ dyes on the performance of dye-sensitized solar cells: a density functional theory study. Comput Theor Chem 1015:8-14.

32. Feng J, Jiao Y, Ma W, Nazeeruddin MK, Grätzel M, Meng S (2013) First principles design of dye molecules with ullazine donor for dye sensitized solar cells. J Phys Chem C 117:3772-8.

33. Cao D, Peng J, Hong Y, Fang X, Wang L, Meier H (2011) Enhanced performance of the dye-sensitized solar cells with phenothiazine-based dyes containing double D-A branches. Org Lett 13(7):1610-3. 
34. Yang L, Yao Z, Liu J, Wang J, Wang P (2016) A systematic study on the influence of electron-acceptors in phenanthrocarbazole dye-sensitized solar cells. ACS Appl Mater Interfaces 8:9839-48.

35. Narayan MR (2012) Dye sensitized solar cells based on natural photosensitizers. Renew Sust Energy Rev 16:208-15.

36. Zhang J, Li HB, Sun SL, Geng Y, Wu Y, Su ZM (2012) Density functional theory characterization and design of high-performance diarylamine-fluorene dyes with different $\pi$ spacers for dye-sensitized solar cells. J Mater Chem 22:568-576.

37. Preat J, Jacquemin D, Michaux C, Perpète EA (2010) Improvement of the efficiency of thiophene-bridged compounds for dye-sensitized solar cells. Chem Phys 376:56-68.

38. Katoh R, Furube A, Yoshihara T, Hara K, Fujihashi G, Takano S, Murata S, Arakawa H, Tachiya M (2004) Efficiencies of electron injection from excited N3 dye into nanocrystalline semiconductor $\left(\mathrm{ZrO}_{2}, \mathrm{TiO}_{2}, \mathrm{ZnO}, \mathrm{Nb}_{2} \mathrm{O}_{5}, \mathrm{SnO}_{2}, \mathrm{In}_{2} \mathrm{O}_{3}\right)$ films. J Phys Chem B 108:4818-4822.

39. Zhang J, Kan YH, Li HB, Geng Y, Wu Y, Su ZM (2012) How to design proper $\pi$-spacer order of the D- $\pi$-A dyes for DSSCs? A density functional response. Dyes Pigm 95:31321.

40. Daeneke T, Mozer AJ, Uemura Y, Makuta S, Fekete M, Tachibana Y, Koumura N, Bach U, Spiccia L (2012) Dye regeneration kinetics in dye-sensitized solar cells. J Am Chem Soc 134:16925-16928.

41. Marinado T, Nonomura K, Nissfolk J, Karlsson MK, Hagberg DP, Sun L, Mori S, Hagfeldt A (2009) How the nature of triphenylamine-polyene dyes in dye-sensitized solar cells affects the open-circuit voltage and electron lifetimes. Langmuir 26 2592-2598.

42. Rühle S, Greenshtein M, Chen SG, Merson A, Pizem H, Sukenik CS, Cahen D, Zaban A. Molecular adjustment of the electronic properties of nanoporous electrodes in dyesensitized solar cells. J Phys Chem B (2005) 109:18907-18913.

43. Stephens PJ, Devlin FJ, Chabalowski CF, Frisch MJ (1994) Ab initio calculation of vibrational absorption and circular dichroism spectra using density functional force fields. J Phys Chem 98:11623-11627. 
44. Arunkumar A, Anbarasan PM (2018) Highly efficient organic indolocarbazole dye in different acceptor units for optoelectronic applications - a first principle study. Struct Chem 29:967-976.

45. Meng S, Kaxiras E, Nazeeruddin MK, Grätzel M (2011) Design of dye acceptors for photovoltaics from first-principles calculations. J Phys Chem C 115:9276-9282.

46. Yanai T, Tew DP, Handy NC (2004) A new hybrid exchange-correlation functional using the Coulomb-attenuating method (CAM-B3LYP). Chem Phys Lett 393:51-57.

47. Perdew JP, Burke K, Wang Y (1996) Erratum: Generalized gradient approximation for the exchange-correlation hole of a many-electron system. Phys Rev B 54:533.

48. Lin YS, Li GD, Mao SP, Chai JD (2012) Long-range corrected hybrid density functionals with improved dispersion corrections. J Chem theory Comput 9:263-272.

49. Ordon P, Tachibana A (2005) Investigation of the role of the C-PCM solvent effect in reactivity indices. J Chem Sci 117:583-589.

50. Arunkumar A, Anbarasan PM (2019) Optoelectronic Properties of a Simple Metal-Free Organic Sensitizer with Different Spacer Groups: Quantum Chemical Assessments. J Electron Mater 48:1522-1530.

51. O'boyle NM, Tenderholt AL, Langner KM (2008) Cclib: a library for package-independent computational chemistry algorithms. J Comput Chem 29:839-45.

52. Frisch MJ, Trucks GW, Schlegel HB, Scuseria GE, Robb MA, Cheeseman JR, Scalmani G, Barone V, Mennucci B, Petersson GA, Nakatsuji H, Caricato M, Li X, Hratchian HP, Izmaylov AF, Bloino J, Zheng G, Sonnenberg JL, Hada M, Ehara M, Toyota K, Fukuda R, Hasegawa J, Ishida M, Nakajima T, Honda Y, Kitao O, Nakai H, Vreven T, Montgomery Jr JA, Peralta JE, Ogliaro F, Bearpark MJ, Heyd J, Brothers EN, Kudin KN, Staroverov VN, Kobayashi R,Normand J, Raghavachari K, Rendell AP, Burant JC, Iyengar SS, Tomasi J, Cossi M, Rega N, Millam NJ, Klene M, Knox JE, Cross JB, Bakken V, Adamo C, Jaramillo J, Gomperts R, Stratmann RJ, Yazyev O, Austin AJ, Cammi R, Pomelli C, Ochterski JW, Martin RL, Morokuma K, Zakrzewski VG, Voth GA, Salvador P, Dannenberg JJ, Dapprich S, Daniels AD, Farkas Ö, Foresman JB, Ortiz JV, Cioslowski J, Fox DJ, Gaussian 09, Gaussian Inc., Wallingford, CT, USA, 2009. 
53. Jungsuttiwong S, Tarsang R, Sudyoadsuk T, Promarak V, Khongpracha P, Namuangruk S (2013) Theoretical study on novel double donor-based dyes used in high efficient dyesensitized solar cells: the application of TDDFT study to the electron injection process. Org Electron 14:711-722.

54. Asbury JB, Wang YQ, Hao E, Ghosh HN, Lian T (2001) Evidences of hot excited state electron injection from sensitizer molecules to $\mathrm{TiO}_{2}$ nanocrystalline thin films. Res Chem Intermed 27:393-406.

55. Gong J, Liang J, Sumathy K (2012) Review on dye-sensitized solar cells (DSSCs): fundamental concepts and novel materials. Renew Sust Energ Rev 16:5848-5860.

56. Islam A, Sugihara H, Arakawa H (2003) Molecular design of ruthenium (II) polypyridyl photosensitizers for efficient nanocrystalline $\mathrm{TiO}_{2}$ solar cells. J Photoch Photobio A: Chem 158:131-138.

\section{Figure Captions}

Scheme 1 Outlining of molecular structures for D- $\pi$-A System.

Fig. 1 Optimized geometric structures of SB and designed dye molecules were calculated at B3LYP/6-31G(d,p) level of set.

Fig. 2 The selected frontier molecular orbitals of the Planned dyes and SB were implemented on B3LYP/6-31G(d,p) level of theory.

Fig. 3 The energy levels of the SB and PT-BTBA, PT-EBTBA, PT-EBTEBA dyes are calculated at B3LYP/6-31G(d,p) theory.

Fig. 4 TD-DFT absorption spectra of designed sensitizers and SB are calculated at CAM-B3LYP/6-311++G(d,p) level of basis set in THF medium.

Fig. 5a,5b,5c Light harvesting efficiency, open-circuit photovoltage and exciton binding energy of the SB, planned dyes were performed by the CAM-B3LYP/6-311++G(d,p) level of theory.

\section{Supporting Information}

Fig. S0 Dipole moment of the SB and designed molecules are calculated by B3LYP/6$31 \mathrm{G}(\mathrm{d}, \mathrm{p})$ level of theory.

\section{Highlights}

The phenothiazine-based organic dyes are designed and investigated.

* The absorption wavelength PT-EBTEBA was showed better than the SB and other molecules. 
Figures

SB

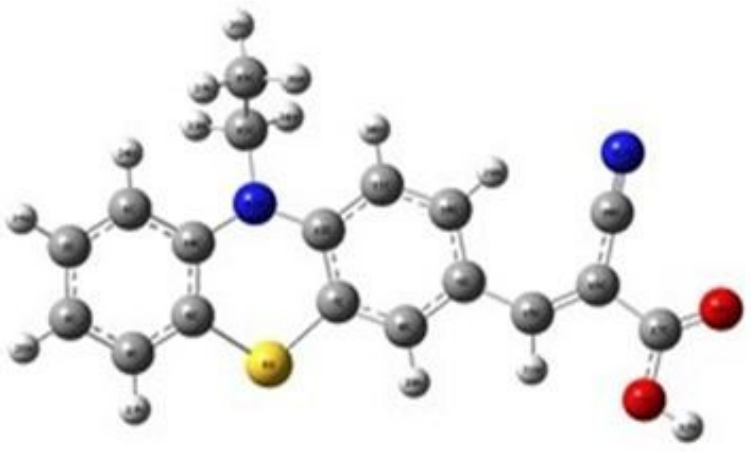

PT-BTBA

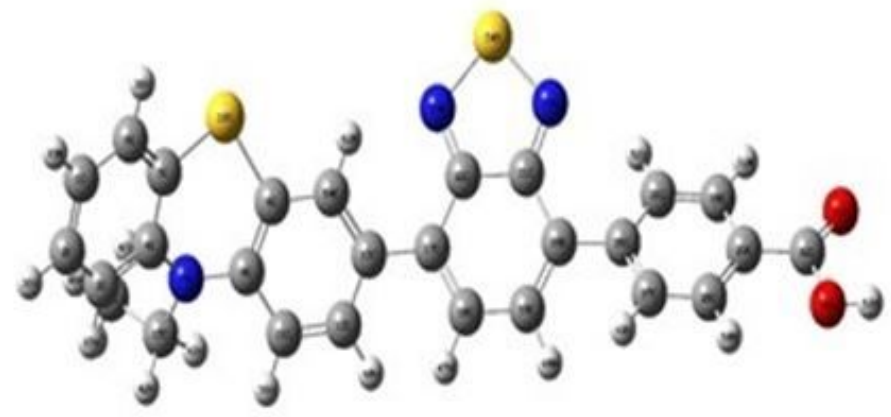

PT-EBTBA

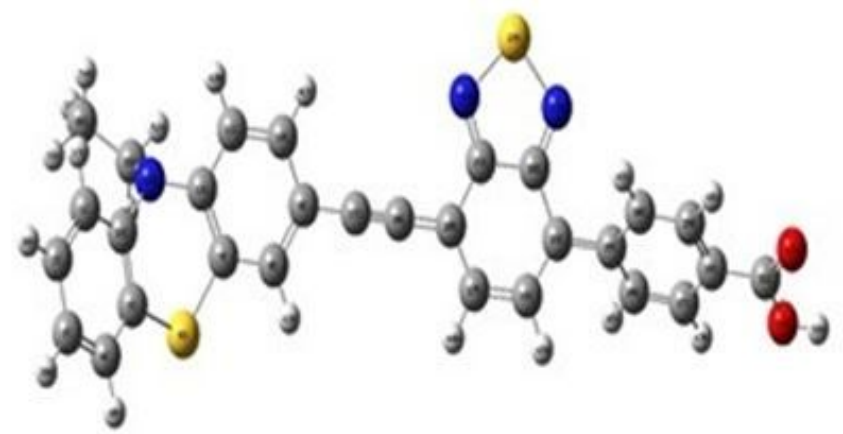

PT-EBTEBA

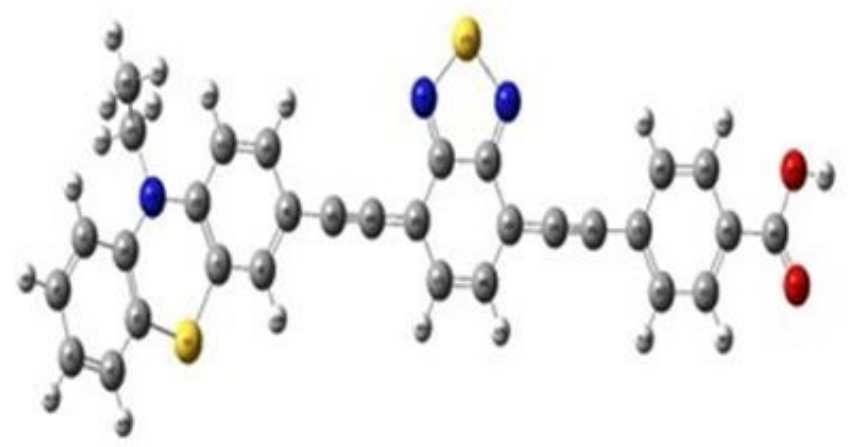

Figure 1

Optimized geometric structures of SB and designed dye molecules were calculated at B3LYP/6-31G(d,p) level of set. 
Dyes

SB

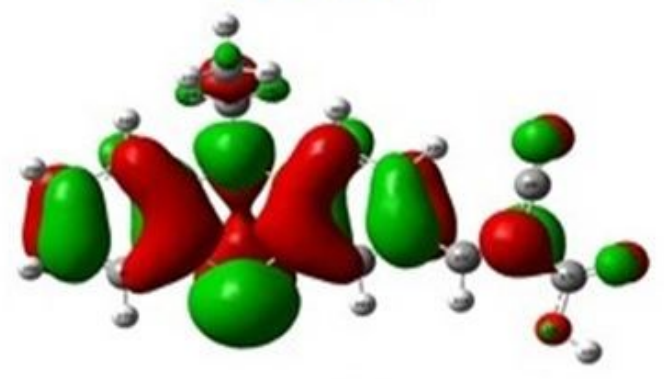

PT-BTBA

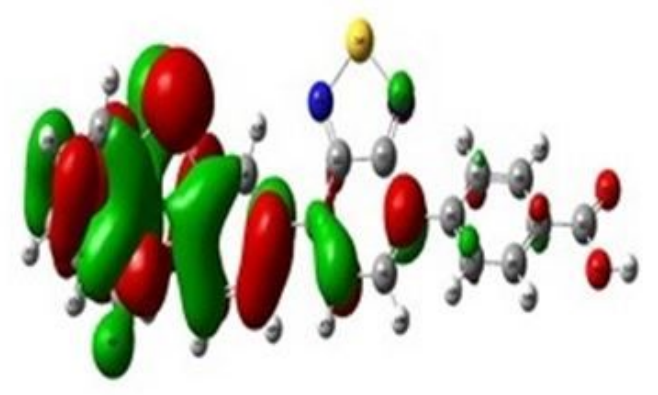

PT-EBTBA
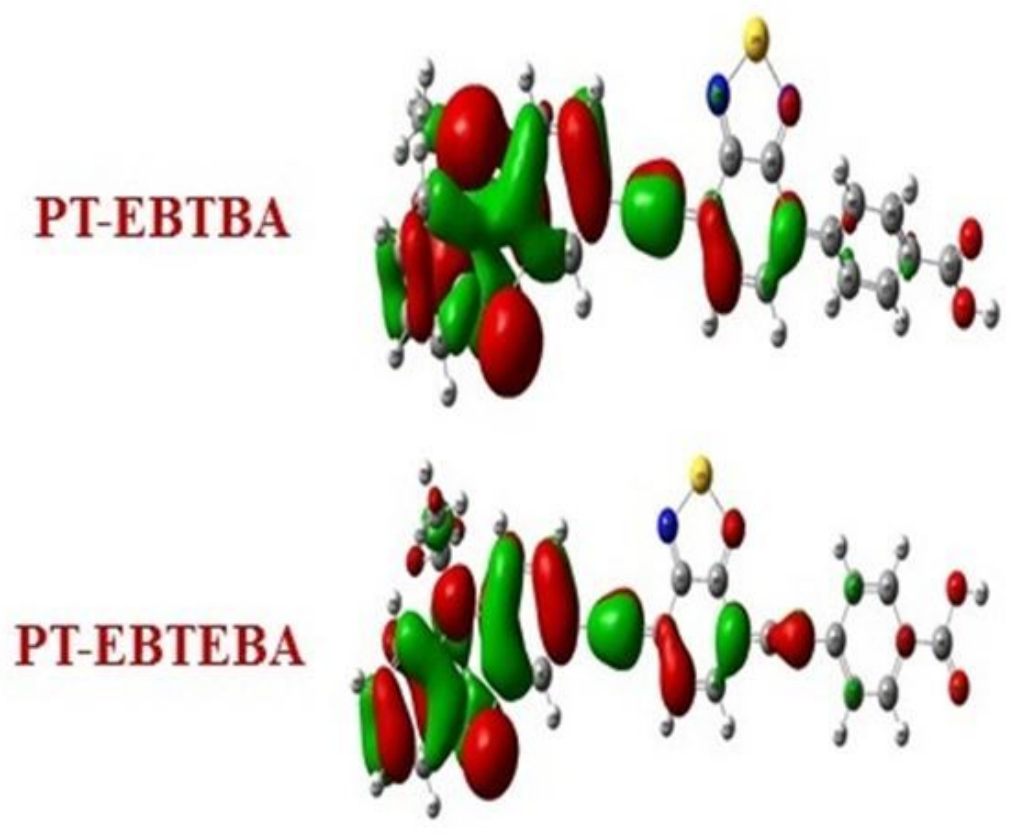

\section{LUMOs}
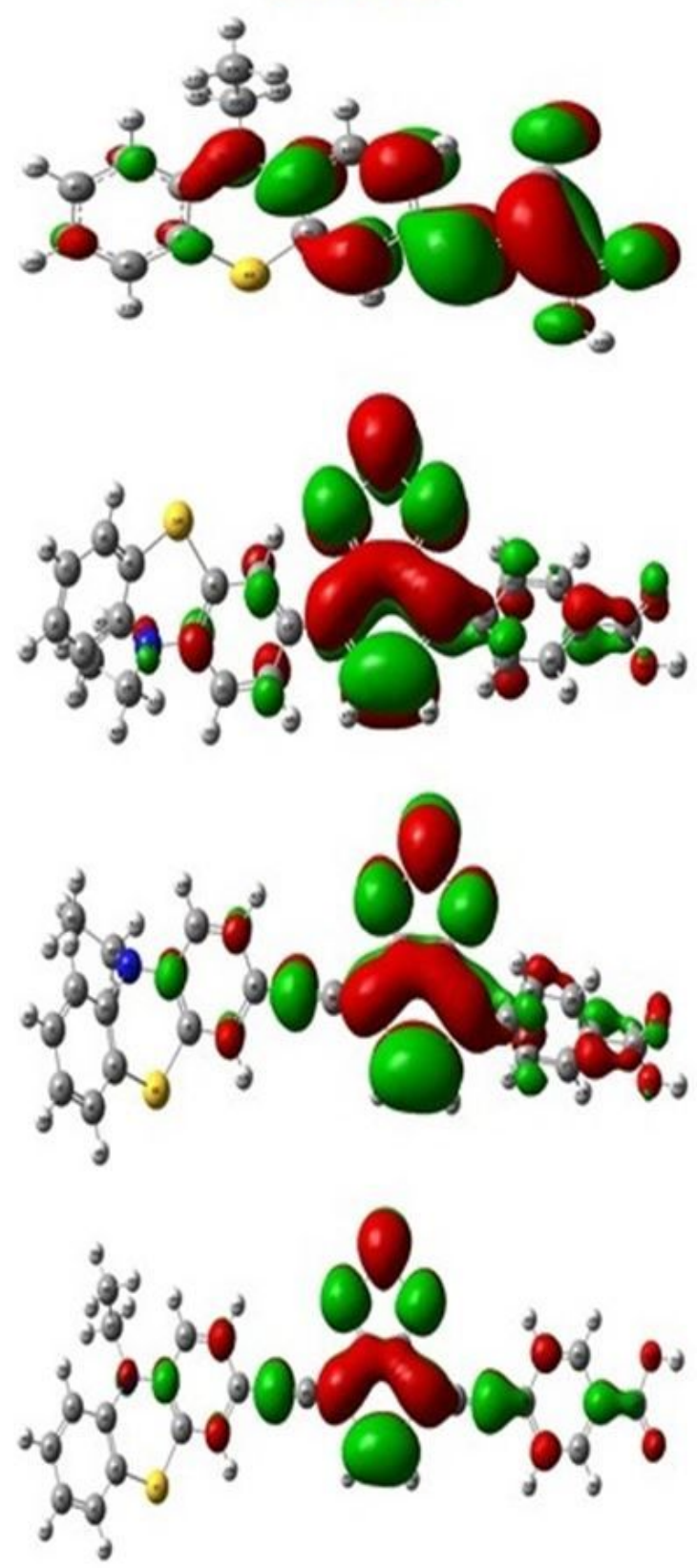

Figure 2

The selected frontier molecular orbitals of the Planned dyes and SB were implemented on B3LYP/6$31 \mathrm{G}(\mathrm{d}, \mathrm{p})$ level of theory. 


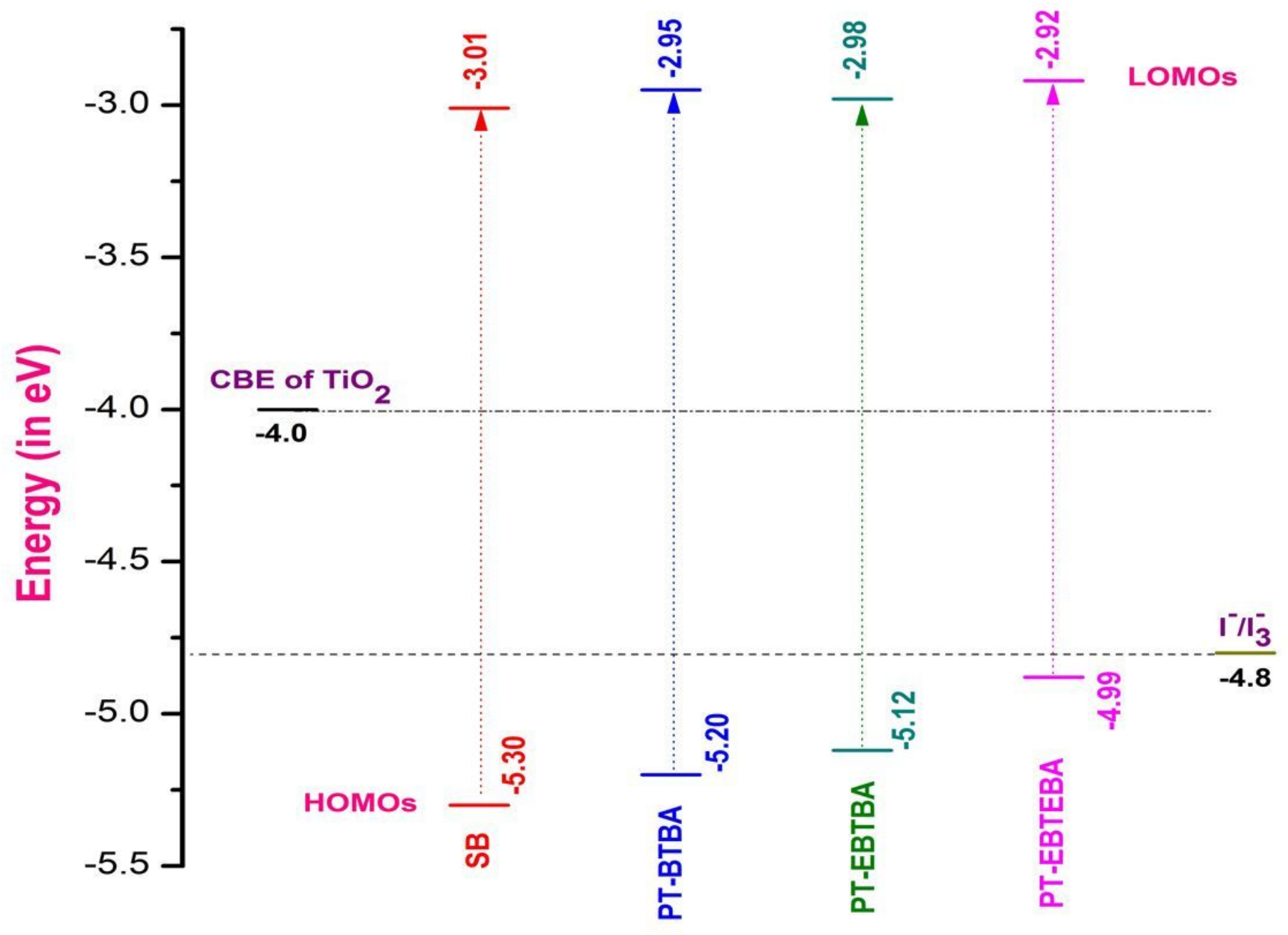

Figure 3

The energy levels of the SB and PT-BTBA, PT-EBTBA, PT-EBTEBA dyes are calculated at B3LYP/6-31G(d,p) theory. 


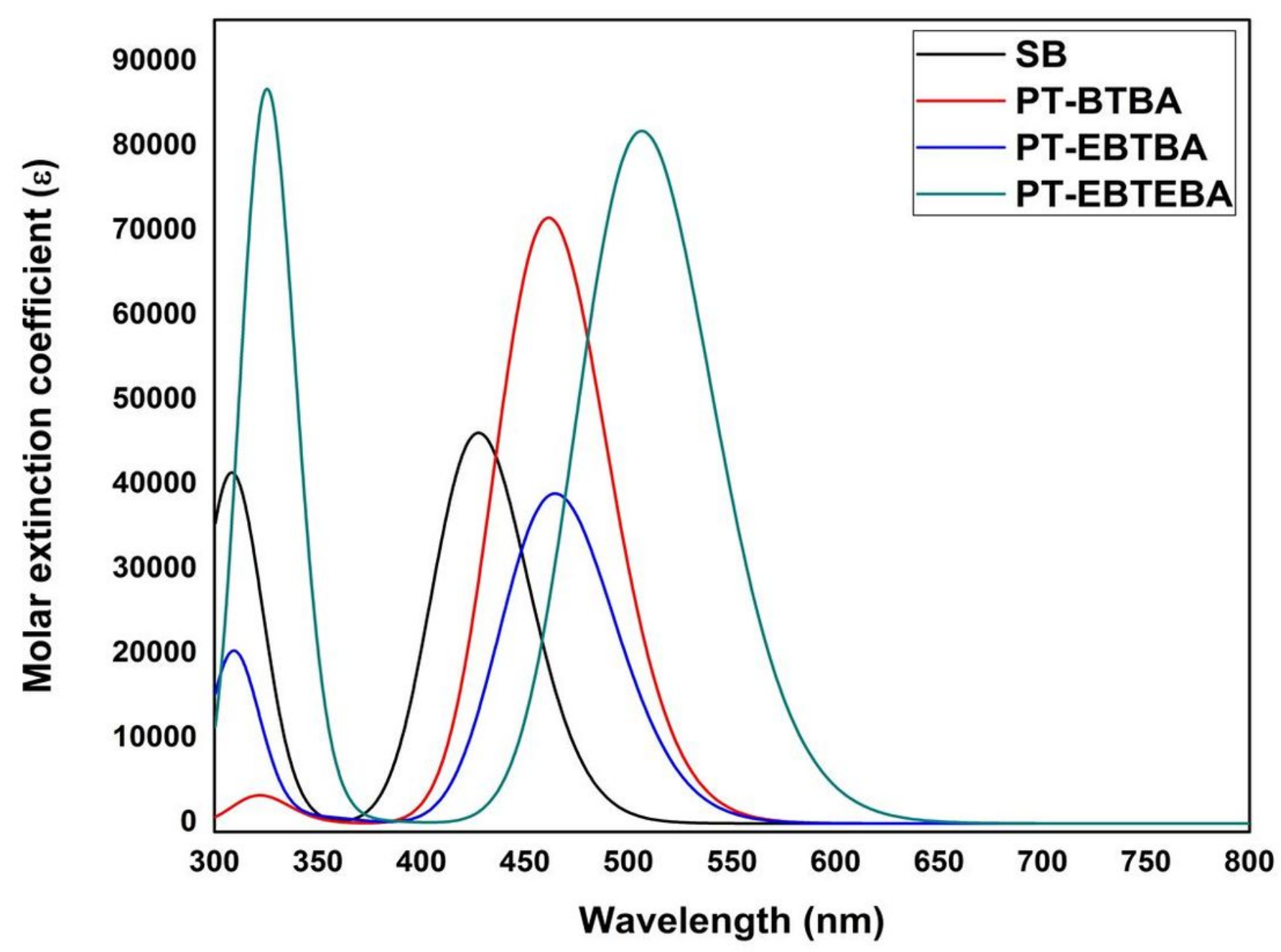

Figure 4

TD-DFT absorption spectra of designed sensitizers and SB are calculated at CAM-B3LYP/6-311++G(d,p) level of basis set in THF medium. 

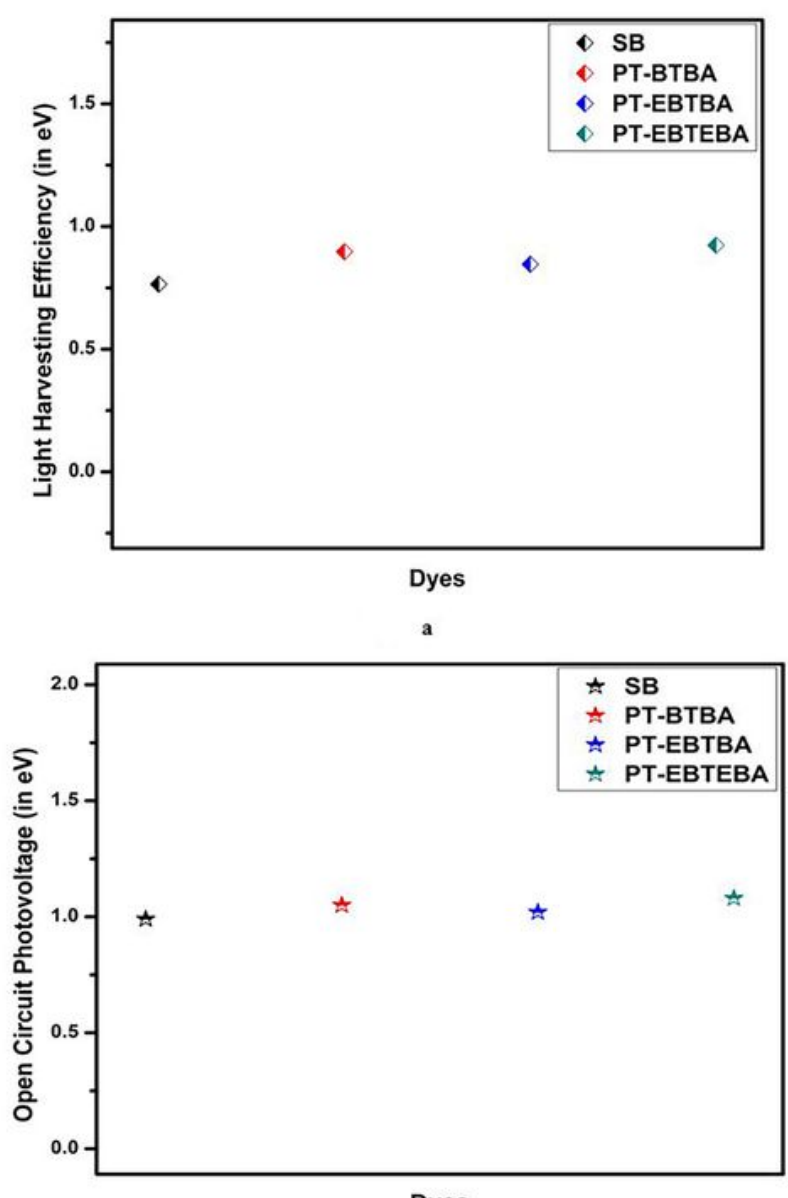

Dyes

b

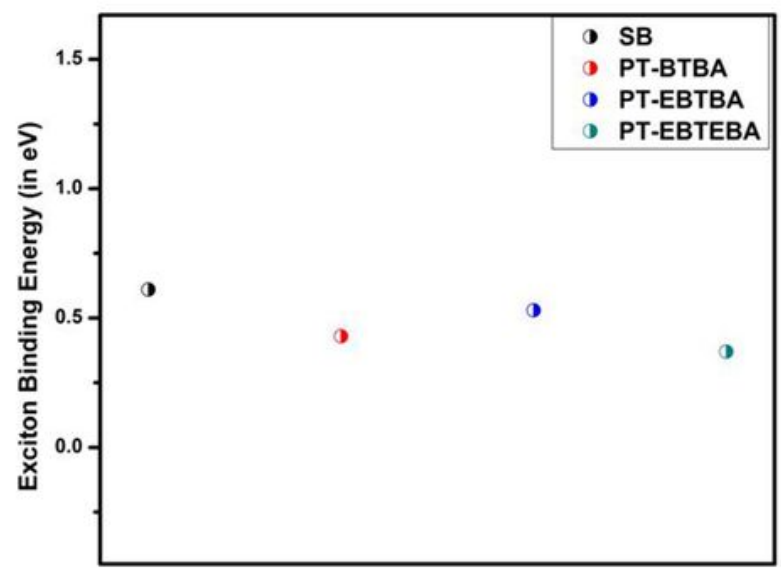

Dyes

c

Figure 5

Light harvesting efficiency, open-circuit photovoltage and exciton binding energy of the SB, planned dyes were performed by the CAM-B3LYP/6-311++G(d,p) level of theory.

\section{Supplementary Files}


This is a list of supplementary files associated with this preprint. Click to download.

- scheme1.jpg

- Supportinginformation.doc 